\title{
ADAPTIVE EVOLUTION OF PLASTIC FORAGING RESPONSES IN A CLONAL PLANT
}

\author{
MARK VAN KLEUnen ${ }^{1}$ AND MARKus Fischer \\ Institute for Environmental Science, University of Zürich, Winterthurerstrasse 190, CH-8057 Zürich, Switzerland
}

\begin{abstract}
Stoloniferous rosette plants may show horizontal and vertical foraging responses, such as changes in branching frequency, stolon internode length, leaf length, and height growth of stolons. To study whether such plastic foraging responses constitute an adaptation to heterogeneity in competition, we studied genetic variation in and fitness consequences of plastic foraging responses in the stoloniferous lake-shore plant Ranunculus reptans. Because plastic foraging responses are likely to have been more strongly selected for in heterogeneous environments, we used 15 genotypes from competitive, heterogeneous microhabitats and 15 from competition-free, homogeneous microhabitats from Lake Constance (central Europe).

We planted vegetatively propagated rosettes of the 30 genotypes (totaling 236 rosettes) into a greenhouse environment with spatially heterogeneous competition. Four replicates of each genotype were planted into the competition-free halves of experimental trays, and four other replicates into the halves with the naturally co-occurring grass Agrostis stolonifera.

We found significant variation among genotypes in vertical and horizontal foraging responses. In line with the hypothesis of adaptive plasticity, genotypes from the competitive heterogeneous microhabitats more strongly increased the vertical angle of the first stolon internode (126\%) and the specific stolon length (166\%) in response to competition than genotypes from the competition-free homogeneous microhabitats. Moreover, we found that genotypes that were more plastic in the vertical angle of the first stolon internode, stolon height, and specific internode length produced more rosettes and flowers than less plastic genotypes (all selection gradients for plasticity $>0.316$ ).

Our findings strongly suggest that plastic foraging responses constitute an adaptation to environmental heterogeneity, at least in the stoloniferous $R$. reptans.
\end{abstract}

Key words: adaptive phenotypic plasticity; clonal growth; foraging responses; genetic variation; local adaptation; Ranunculus reptans; selection-gradient analysis.

\section{INTRODUCTION}

Many plants, especially spreading clonal plants, experience spatial environmental heterogeneity. In clonal plants, this heterogeneity may be alleviated by the exchange of resources between interconnected clone parts (Pitelka and Ashmun 1985). Furthermore, spreading stoloniferous or rhizomatous plants have the potential to selectively place ramets in benign patches and to escape from adverse ones by means of plasticity in internode length and branching frequency (Harper 1981, Bell 1984, Hutchings and Slade 1988, Schmid 1990, Hutchings and de Kroon 1994). Such plastic responses are analogous to habitat-selection behavior in animals and have therefore frequently been called "foraging" responses (Bell 1984, Bazzaz 1991). Foraging responses are not restricted to the horizontal plane. In rosette plants, vertical foraging is possible by means of plasticity in leaf length (Hutchings and de Kroon 1994, Huber 1996, Huber et al. 1998). Moreover, in some clonal plants, stolons do not grow strictly horizontally but may also show height growth.

Manuscript received 25 September 2000; revised 1 December 2000; accepted 7 December 2000; final version received 29 January 2001.

${ }^{1}$ E-mailvkleunen@uwinst.unizh.ch
Foraging responses have been reported for several clonal plants (e.g., Schmid 1986, Slade and Hutchings $1987 a, b$, Solangaarachchi and Harper 1987, de Kroon and Knops 1990, Dong and Pierdominici 1995). Implicitly it was assumed that plastic foraging responses in clonal plants constitute an adaptation to spatial environmental heterogeneity (Hutchings and de Kroon 1994), although this is not necessarily true (Bradshaw 1965, Gould and Lewontin 1978). If foraging responses are in the process of adaptation, they should have a genetic component and a selective advantage. Therefore, it needs to be tested whether there is genetic variation in plastic foraging responses, and whether they increase plant fitness (Lewontin 1984, Via 1987).

Most studies on foraging responses in clonal plants have been carried out with one or two genotypes or with material of unknown genetic origin. Such studies cannot reveal whether there is genetic variation in foraging responses, and thus whether foraging responses can be modified by selection (de Kroon et al. 1994). Moreover, if there is genetic variation in foraging responses, studies based on only a few genotypes need not to be representative for the species and could even lead to erroneous conclusions. In the few cases where foraging responses were studied with several genotypes, fitness consequences were either not studied 


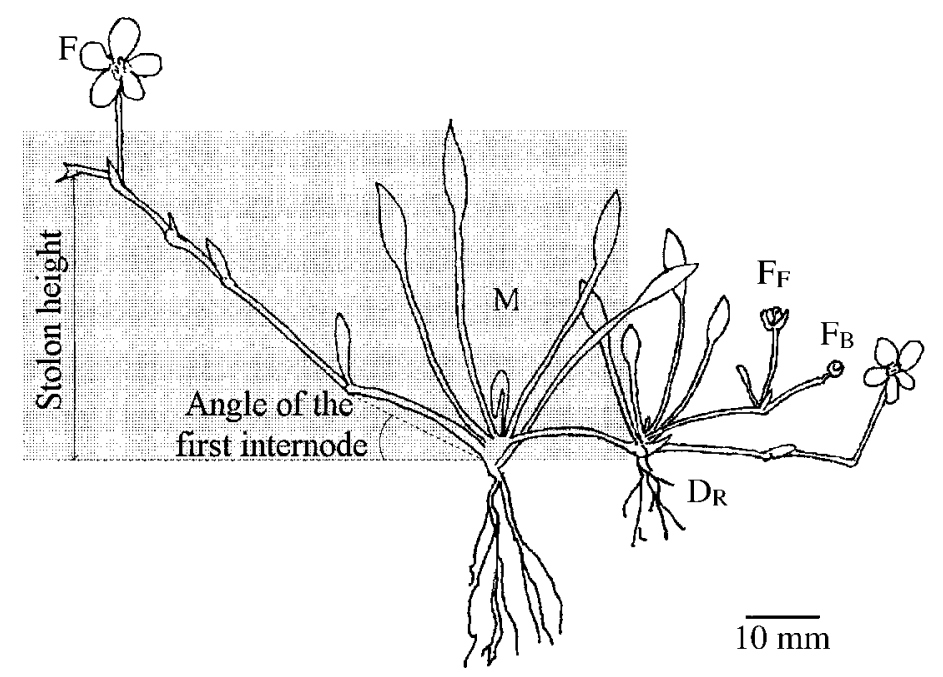

FIG. 1. Schematic illustration of a plant of Ranunculus reptans. Each rosette may be rooted (vegetative reproduction) and may produce one single flower (sexual reproduction). The diagram also illustrates the vertical growth response of a stolon branch to competition by grass (shaded area). $\mathrm{M}=$ mother rosette, $\mathrm{D}_{\mathrm{R}}=$ rooted daughter rosette, $\mathrm{F}=$ flower, $\mathrm{F}_{\mathrm{F}}=$ fruits, and $\mathrm{F}_{\mathrm{B}}=$ flower bud.
(Cheplick 1997, Skálová et al. 1997, Cheplick and Gutierrez 2000) or no benefits were found (Humphrey and Pyke 1997). Therefore, studies are needed that specifically test whether plastic foraging responses constitute an adaptation in clonal plants.

Clonal plants are very convenient for studying plasticity, because genotypes can easily be replicated and grown in different environments to estimate genotypic values of plasticity. Then fitness consequences of plastic foraging responses can be assessed by using selection-gradient analyses in which average genotypic values of fitness measures are regressed on genotypic values of plasticity in foraging traits (Lande and Arnold 1983, Weis and Gorman 1990, Schmitt et al. 1999). In such analyses, benefits of plastic foraging responses are indicated by positive regression coefficients.

To study whether foraging responses are in the process of adaptation, we studied genetic variation in and fitness consequences of foraging responses in the stoloniferous herb Ranunculus reptans (Fig. 1). This species was chosen because in its natural habitats at periodically inundated lake shores it frequently grows along a gradient between two microhabitat types that, although only 5-10 m apart, differ greatly in the level of competition (Prati and Peintinger 2000). Foraging responses of the weak competitor $R$. reptans may be especially beneficial in the competitive microhabitat that is more heterogeneous than the competition-free microhabitat because of variation in the density of competing graminoids. Therefore, if foraging responses are adaptive, they should be more likely to have been selected for in the competitive heterogeneous microhabitat than in the competition-free homogeneous one.

In a greenhouse experiment, we used 30 different genotypes of $R$. reptans representing the two different microhabitat types to study both horizontal and vertical foraging in response to competition and their consequences for plant fitness. We planted vegetatively prop- agated rosettes of the genotypes into a spatially heterogeneous competitive environment. Rosettes were either planted into patches without competition or into patches with Agrostis stolonifera, which is the naturally most abundant co-occurring grass species. As measures of foraging, we recorded the direction of stolon initiation, branching frequency, length of stolon internodes, leaf length, the vertical angle of the first internode, and stolon height. To test whether plastic foraging responses increase fitness, we used selection-gradient analyses.

We asked the following specific questions: (1) Do plants of $R$. reptans show plastic foraging responses? (2) Is there variation among genotypes in foraging responses, and (3) if so, is this related to the type of microhabitat from which genotypes originated? (4) Are the foraging responses beneficial in the spatially heterogeneous competitive environment of our study? We discuss whether vertical and horizontal foraging are likely to constitute an adaptation in $R$. reptans.

\section{Methods}

Study species

The stoloniferous, rosette-forming herb Ranunculus reptans L. (Ranunculaceae) has a circumpolar distribution, mainly in the temperate-to-boreal subarctic zones of Europe, Asia, and North America (Hess et al. 1980). Ranunculus reptans mainly inhabits periodically inundated lake shores with low vegetation cover. Because of the regulation of water levels of most lakes, $R$. reptans has become a rare species in Central Europe, where it is now restricted to a few lakes in the foothill zone of the Alps (Prati and Peintinger 2000). Today most populations in Central Europe are found around Lake Constance. Within these populations, there is a consistent gradient between microhabitats, which is likely to have existed already for thousands of years because these populations most likely represent relicts 
Plate 1. Two experimental trays with the grass Agrostis stolonifera as a competitor in each half of the tray. The conspicuous dots are flowers of our target species, Ranunculus reptans. Photograph by Mark van Kleunen.

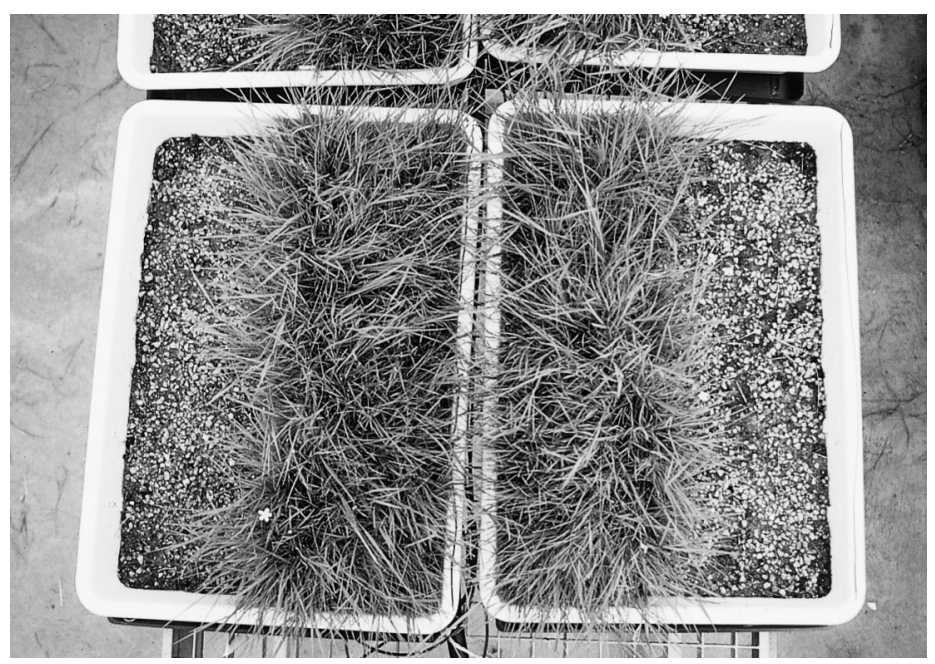

from the last ice age (Prati and Peintinger 2000). Plants growing close to the winter water level ("lakeside") experience an average summer-inundation period of $150 \mathrm{~d}$ and little competition with other species. In contrast, plants growing about $30 \mathrm{~cm}$ higher and $5-10 \mathrm{~m}$ further away from the water ("landside") experience an average summer-inundation period of $80 \mathrm{~d}$ and heterogeneous competition with graminoids, frequently Agrostis stolonifera (Prati 1998).

Rosettes of $R$. reptans may have up to 20 leaves. Rosettes may form stolon branches from meristems in the axils of leaves (Fig. 1). Leaf blades, which are gradually narrowing into the petioles, are $10-50 \mathrm{~mm}$ long and 1-5 mm wide. Stolons grow sympodially and consist of rosettes (ramets) connected by thin (0.5-2 $\mathrm{mm}$ diameter) stolon internodes with a length of 3-5 $\mathrm{cm}$. Stolon branches can grow $10-20 \mathrm{~cm}$ within one growing season. Each rosette has the potential to root, to produce one flower, and to produce one or more side branches (Prati and Peintinger 2000; Fig. 1). The production of stolon branches is interrupted by the summer inundation period, during which stolon internodes decay (Daniel Prati [UFZ Centre for Environmental Research, Halle/Saale, Germany], personal communication).

\section{Plant material}

We collected equal numbers (4-5) of landside and lakeside plants from each of nine populations (totaling 82 plants) around Lake Constance in 1995 and 1997. The distance to the nearest neighbor population ranged from 1.6 to $32.6 \mathrm{~km}$ (Fischer et al. 2000), and distances between sampled plants were $\geq 5 \mathrm{~m}$ in all cases. Random amplified polymorphic DNA (RAPD) analysis revealed that all 82 plants represented different genotypes (Fischer et al. 2000). After collected plants had been propagated repeatedly, vegetative offspring of these genotypes were planted into 12 -cm-diameter pots filled with a 4:1 mixture of sand : compost and kept in a greenhouse. To test whether there is genetic differentiation between genotypes representing the two different microhabitat types, we randomly selected 15 landside genotypes and 15 lakeside genotypes out of the 82 sampled plants for our experiment independent of population of origin.

On 2 December 1998 (20 wk before the start of the experiment), we started vegetative propagation of genotypes from single rosettes in $12.5 \times 18 \mathrm{~cm}$ trays filled with a $4: 1$ mixture of sand and compost. The substrate was enriched with $15 \mathrm{~g} / \mathrm{L}$ of a controlled-release fertilizer (Osmocote Plus $\left[18 \% \mathrm{~N}, 6 \% \mathrm{P}_{2} \mathrm{O}_{5}, 12 \%\right.$ $\mathrm{K}_{2} \mathrm{O}$ ] Grace Sierra International, Heerlen, The Netherlands). Both pre-cultivation of plants and the experiment were performed in a heated greenhouse that transmitted $\sim 60 \%$ of full daylight, and that had additional lighting to extend the light period to $16 \mathrm{~h}$. Lights were also turned on during cloudy day periods. The temperature was kept at $\sim 24^{\circ} \mathrm{C}$ during the light period and at $\sim 16^{\circ} \mathrm{C}$ during the dark period.

\section{Experimental set-up}

On 3 February 1999 (11 wk before the start of the experiment), we filled forty-eight $30 \times 44 \times 8 \mathrm{~cm}$ trays with a 4:1 mixture of sand and compost and covered it with a thin layer of gravel (to prevent growth of algae and to reduce evaporation). In each tray, we created two patches $(15 \times 44 \mathrm{~cm})$ by sowing the grass Agrostis stolonifera as competitor into one half of each tray. Agrostis stolonifera formed a dense matrix with a height of $10-15 \mathrm{~cm}$ and density of $\sim 1 \mathrm{plant} / \mathrm{cm}^{2}$, comparable to densities found in the natural habitat of $R$. reptans at Lake Constance. We clipped leaves and stolons of A. stolonifera several times during the experiment to diminish differences between trays and to preserve the border between the patches.

We planted a total of five plants into each tray, and each plant had been randomly assigned to the competitive or competition-free half of the tray. Horizontal 
foraging responses may only result in effective ramet placement when plants grow in an environment that is spatially heterogeneous at a scale relevant to the plant (Stuefer 1996). Seedlings of Portulaca oleracea can already detect neighboring plants at a distance of $3 \mathrm{~cm}$ (Novoplansky et al. 1990). Therefore, to enhance the likelihood that plants of $R$. reptans detect the presence of the other patch, planting positions were situated close (2-cm distance) to the other patch. On 19 April 1999 we randomly assigned eight rosettes of each of the 30 genotypes (totaling 236 plants; one genotype was represented by four rosettes only) to one of the 240 planting positions in the 48 trays with the limitations that half of the replicates per genotype were planted into competition-free patches and that rosettes planted into the same tray belonged to different genotypes. Within trays, growth of $R$. reptans individuals was not limited by the size of the trays, and interference among the individuals was likely to be weak, because rooting zones of the originally planted rosettes did not overlap, and because $R$. reptans plants impose hardly any shading at the densities attained in the experiment.

We assigned the trays to new random positions in the greenhouse weekly. To control for effects of the direction of incident sunlight in the greenhouse, half of the trays were always orientated with the competition-free patch towards the north (north-facing trays) and the other half towards the south (south-facing trays). Three times a week, we watered the plants to full saturation of the soil through holes in the bottom of the trays.

\section{Measurements}

To estimate the initial rosette size, we counted the number of leaves and measured the length of the longest leaf on each planted rosette two days after planting. Because the foraging traits-branching frequency, stolon height, and the vertical angle of the first stolon internode-may depend on the developmental stage of plants (Birch and Hutchings 1992, Huber and Stuefer 1997), we measured these traits when plants had produced five daughter rosettes along the main axis of their longest stolon branch (Fig. 1). Half of the 144 plants that reached this stage during the experiment had been planted into the competition-free halves of the trays (73), and the other half into the competitive halves (71). We assessed stolon height as the distance between the fifth daughter rosette and the soil surface.

Eleven weeks after the start of the experiment, we harvested the plants. As fitness measures, we counted the number of rosettes, of rooted rosettes (as a measure of vegetative reproduction), and of flowers (as a measure of sexual reproduction) of each plant, and determined total plant biomass after drying the plants to constant mass at $70^{\circ} \mathrm{C}$. As traits of horizontal and vertical foraging, we determined the direction (planting patch or neighboring patch) into which the longest stolon branch had been initiated (i.e., the direction of the first internode) from originally planted rosettes, and measured the length of each of the first four internodes on this branch and the length of the longest leaf of the originally planted rosettes.

Observed plasticity in internode length is likely to be determined by both internode elongation in response to shading (i.e., "active plasticity") and internode shortening as a consequence of resource limitation (i.e., "passive plasticity"). To control for passive plasticity, we calculated the specific internode length by dividing the length of the first four internodes by their biomass.

\section{Statistical analyses}

We analyzed quantitative variables with mixed-model analyses of variance (Norusis 1999). We considered "planting patch" (competitive, competition-free), "orientation of patches" (south facing, north facing), and "microhabitat of origin" (landside, lakeside) as fixed factors, and "genotype" as a random factor.

Biomass, number of rosettes, number of rooted rosettes, number of flowers, and specific length of the first four internodes were log-transformed to achieve normality and homoscedasticity. Because rosettes were not standardized for size at the start of the experiment, we considered the initial number of leaves and the initial length of the longest leaf as covariates in the analysis of fitness measures (biomass, number of rosettes, of rooted rosettes, and of flowers). Similarly, we considered the initial length of the longest leaf as a covariate in the analysis of the length of the longest leaf.

We analyzed the binary data on the direction of stolon initiation (towards the planting patch or the neighboring patch) with logistic regression. For this analysis, we used the same model as for the analyses of variance and tested significance using ratios of mean deviance changes (quasi $F$ values), which approximately follow the $F$ distribution (Payne et al. 1993). For logistic regression, we used the statistical software Genstat (Lawes Agricultural Trust, Institute of Arable Crops Research, Rothamsted, UK; Payne et al. 1993).

To test whether plastic foraging responses to competition increase the average fitness of a genotype $(j)$, we regressed genotypic values of fitness measures averaged over the two planting patches $\left(\bar{W}_{j}\right)$ on genotypic values of foraging traits averaged over the two planting patches (i.e., elevation of the reaction norm, $\bar{Z}_{j}$ ) and on genotypic values of plasticity in foraging traits (i.e., steepness of the reaction norm, $\bar{P}_{j}$ ), adapted from Weis and Gorman (1990: Eq. 6):

$$
\bar{W}_{j}=\text { Constant }+\alpha \bar{Z}_{j}+\beta \bar{P}_{j} .
$$

Because only a positive regression coefficient of fitness on plasticity (i.e., a positive selection gradient) indicates a benefit of plastic foraging, we used onetailed significance tests. To allow comparisons between regression coefficients for different traits and for different fitness measures, we expressed them in units of $1 \mathrm{SD}$. 
TABLE 1. The effect of competition in the planting patch on fitness, and on vertical and horizontal foraging traits of Ranunculus reptans.

\begin{tabular}{|c|c|c|}
\hline \multirow[b]{2}{*}{ Traits } & \multicolumn{2}{|c|}{ Planting patch } \\
\hline & Competition-free & Competitive \\
\hline \multicolumn{3}{|l|}{ Fitness measures } \\
\hline Total biomass (mg) & $57.3 \pm 2.8 / 2.7$ & $41.2 \pm 2.0 / 1.9$ \\
\hline Number of rosettes & $9.0 \pm 0.4 / 0.4$ & $7.8 \pm 0.3 / 0.3$ \\
\hline Number of rooted rosettes & $2.3 \pm 0.1 / 0.0$ & $2.0 \pm 0.0 / 0.0$ \\
\hline Number of flowers & $2.7 \pm 0.2 / 0.2$ & $2.1 \pm 0.2 / 0.1$ \\
\hline \multicolumn{3}{|l|}{ Vertical foraging traits } \\
\hline Vertical angle of first internode $\left(^{\circ}\right)$ & $26.5 \pm 2.7$ & $53.5 \pm 2.3$ \\
\hline Stolon height $(\mathrm{mm})$ & $54.5 \pm 2.9$ & $81.9 \pm 2.7$ \\
\hline Length of the longest leaf $(\mathrm{mm})$ & $37.7 \pm 1.1$ & $41.4 \pm 1.1$ \\
\hline \multicolumn{3}{|l|}{ Horizontal foraging traits } \\
\hline $\begin{array}{l}\text { Proportion of stolons initiated } \\
\text { in direction of neighboring patch }\end{array}$ & $0.306 \pm 0.044$ & $0.372 \pm 0.048$ \\
\hline Combined length of the first four internodes $(\mathrm{mm})$ & $99.7 \pm 2.4$ & $107.5 \pm 2.1$ \\
\hline Specific length of the first four internodes $(\mathrm{mm} / \mathrm{mg}$ ) & $8.5 \pm 0.2 / 0.2$ & $10.0 \pm 0.3 / 0.3$ \\
\hline \multicolumn{3}{|c|}{$\begin{array}{l}\text { Notes: Data are means } \pm 1 \mathrm{SE} \text { for nontransformed data, and } \pm \text { upper } 1 \mathrm{SE} / \text { lower } 1 \mathrm{SE} \text { for } \\
\text { log-transformed data after back transformation (i.e., for all fitness measures plus specific length } \\
\text { of the first four internodes). Differences between patches were significant for all traits, except } \\
\text { for the proportion of stolons initiated in the direction of the neighboring patch. Experimental } \\
\text { plants represented } 30 \text { genotypes sampled from microhabitats of two types }\end{array}$} \\
\hline
\end{tabular}

\section{RESULTS}

\section{Growth and reproduction}

After 11 weeks, plants of Ranunculus reptans on average had a total biomass of $48.6 \mathrm{mg}, 1.4$ stolon branches, and 8.4 rosettes of which 2.2 were rooted and 2.4 bore a flower. Plants planted into the competitive patches had produced significantly less biomass $(-28 \%)$ and fewer rosettes $(-13 \%)$, rooted rosettes $(-13 \%)$, and flowers $(-22 \%)$ than those planted into the competition-free patches (Tables 1 and 2).

There was significant variation among genotypes in total biomass, and in the number of rosettes and flowers (Table 2). Genotypes originating from the landside microhabitat type produced more rosettes (19\%) than genotypes originating from the lakeside microhabitat type when they were planted into the competition-free patches, and fewer rosettes $(-10 \%)$ when they were planted into the competitive patches (significant microhabitat $\times$ planting patch interaction in Table 2 ). This indicates differentiation in plasticity in fitness traits between genotypes from both microhabitat types. Moreover, variation among genotypes in the effect of competition in the planting patch was significant and marginally significant for the production of biomass and rosettes, respectively (genotype $\times$ planting patch interactions in Table 2).

\section{Vertical foraging responses}

When plants had produced five daughter rosettes along the main axis of their longest stolon branch, the average stolon height was $68.0 \mathrm{~mm}$ and the average vertical angle of the first internode was $39.8^{\circ}$. Stolon height and the vertical angle of the first stolon internode were significantly higher (50\% and $102 \%$, respectively) for plants that had been planted into the competitive patches than for those planted into the competition-free patches (Tables 1 and 3).

There was significant variation among genotypes in the vertical angle of the first stolon internode (Table 3 ). For stolon height, variation among genotypes was marginally significant (Table 3 ). Genotypes originating from the landside microhabitat type were significantly more plastic $(126 \%)$ in the vertical angle of the first internode in response to competition in the planting patch than genotypes originating from the lakeside microhabitat type (Fig. 2, microhabitat $\times$ planting patch interaction in Table 3). For stolon height, there was marginally significant variation among genotypes in their plastic response to competition in the planting patch (Table 3). The plastic response of genotypes originating from the different microhabitat types to competition in the planting patch depended on the orientation of the patches for both the vertical angle of the first internode and stolon height, as indicated by significant microhabitat $\times$ planting patch $\times$ orientation interactions (Table 3). In summary, these results indicate variation among genotypes in the vertical foraging responses angle of the first stolon internode and stolon height, and genetic differentiation between the two microhabitat types.

After $11 \mathrm{wk}$, rosettes planted into the competitive patches had produced significantly longer leaves (10\%) than rosettes planted into the competition-free patches (Tables 1 and 4). Leaf length was significantly affected by the orientation of patches (north-facing trays: 41.1 $\pm 1.1 \mathrm{~mm}$ [mean $\pm 1 \mathrm{SE}$ ], south-facing trays: $37.9 \pm$ $1.1 \mathrm{~mm}$, Table 4). While there was significant variation among genotypes in leaf length, there was no significant variation among genotypes in plasticity in leaf length (nonsignificant genotype $\times$ planting patch interaction in Table 4). 
TABLE 2. Results of ANOVA for effects of initial plant size, competition in planting patch, orientation of patches, genetic variation between microhabitats of origin, and variation among genotypes in fitness measures in the experiment with Ranunculus reptans. Experimental plants represented 30 genotypes sampled from microhabitats of two types.

\begin{tabular}{|c|c|c|c|c|c|c|c|c|c|}
\hline \multirow[b]{2}{*}{ Source of variation } & \multirow[b]{2}{*}{ df } & \multicolumn{2}{|c|}{ Log(biomass) } & \multicolumn{2}{|c|}{$\begin{array}{l}\log (\text { number of } \\
\text { rosettes })\end{array}$} & \multicolumn{2}{|c|}{$\begin{array}{c}\text { Log(number of rooted } \\
\text { rosettes })\end{array}$} & \multicolumn{2}{|c|}{$\begin{array}{l}\log (\text { number of } \\
\text { flowers })\end{array}$} \\
\hline & & MS & $F$ & MS & $F$ & MS & $F$ & MS & $F$ \\
\hline Initial number of leaves & 1 & 0.7820 & $36.25 * * *$ & 0.8100 & $27.11 * * *$ & 0.00148 & 0.23 & 0.7410 & $22.29 * * *$ \\
\hline Initial leaf length & 1 & 0.7470 & $34.63 * * *$ & 0.3710 & $12.42 * * *$ & 0.00709 & 1.10 & 0.5280 & $15.88 * * *$ \\
\hline Planting patch, $\mathrm{P}$ & 1 & 0.9630 & $27.53 * * *$ & 0.1810 & $4.21 *$ & 0.15700 & $43.73 * * *$ & 0.2200 & $4.94 *$ \\
\hline Orientation of patches, $\mathrm{O}$ & 1 & 0.0065 & 0.26 & 0.0141 & 0.33 & 0.00149 & 0.39 & 0.0218 & 0.46 \\
\hline $\mathrm{P} \times \mathrm{O}$ & 1 & 0.0550 & $3.23 \dagger$ & 0.0515 & 1.84 & 0.00298 & 0.57 & 0.1140 & $4.30 *$ \\
\hline Microhabitat of origin, $\mathrm{M}$ & 1 & 0.0313 & 0.45 & 0.0288 & 0.39 & 0.00133 & 0.26 & 0.0089 & 0.08 \\
\hline Genotype(M), G(M) & 28 & 0.0694 & $3.22 * * *$ & 0.0739 & $2.47 * * *$ & 0.00505 & 0.78 & 0.1180 & $3.55 * * *$ \\
\hline $\mathrm{M} \times \mathrm{P}$ & 1 & 0.0730 & 2.09 & 0.1870 & $4.35^{*}$ & 0.00334 & 0.93 & 0.0664 & 1.49 \\
\hline$G(M) \times P$ & 28 & 0.0350 & $1.62 *$ & 0.0430 & $1.44 \dagger$ & 0.00359 & 0.55 & 0.0446 & 1.34 \\
\hline $\mathrm{M} \times \mathrm{O}$ & 1 & 0.0002 & 0.01 & 0.0004 & 0.01 & 0.00060 & 0.16 & 0.0008 & 0.02 \\
\hline $\mathrm{G}(\mathrm{M}) \times \mathrm{O}$ & 28 & 0.0255 & 1.18 & 0.0424 & 1.42 & 0.00379 & 0.59 & 0.0477 & $1.44 \dagger$ \\
\hline $\mathrm{M} \times \mathrm{P} \times \mathrm{O}$ & 1 & 0.0284 & 1.67 & 0.0219 & 0.78 & 0.00290 & 0.56 & 0.01426 & 0.54 \\
\hline$G(M) \times P \times O$ & 27 & 0.0170 & 0.79 & 0.0280 & 0.94 & 0.00521 & 0.81 & 0.02649 & 0.80 \\
\hline Error & 113 & 0.0216 & & 0.0299 & & 0.00647 & & 0.0333 & \\
\hline
\end{tabular}

Notes: All variables were log-transformed prior to analyses. Effects of competition are indicated by significant plantingpatch effects.

$\dagger P<0.1 ; * P<0.05 ; * * * P<0.001$.

\section{Horizontal foraging responses}

By the time stolon branches had produced five daughter rosettes on the main axis, they had produced an average of 0.15 secondary branches. Plants branched $77 \%$ less frequently when they had been planted into a competitive patch than when planted into a competition-free patch $\left(N=144\right.$ plants, $\chi_{1}^{2}=10.06, P<$ $0.01)$.

After $11 \mathrm{wk}$, plants had initiated fewer of their longest stolons into the direction of the other patch than expected from random growth $\left(34.1 \%, \chi_{1}^{2}=5.06, P<\right.$ $0.05)$. This suggests that plants stayed in their patch of origin rather than growing into the other one. However, plants planted into the competitive patches tended to initiate more stolons $(22 \%$, logistic regression: quasi$\left.F_{1,28}=0.75, P>0.05\right)$ into the direction of the other patch than plants planted into the competition-free patches (Table 1).

After $11 \mathrm{wk}$, rosettes planted into the competitive patches had significantly longer stolon internodes $(8 \%)$, and they had produced significantly more internode length per unit of biomass $(18 \%)$ than rosettes planted into the competition-free patches (Tables 1 and 5). The combined length of the first four internodes was significantly affected by the orientation of patches (northfacing trays: $109.0 \pm 2.4 \mathrm{~mm}[$ mean $\pm 1 \mathrm{SE}]$, south-

TABLE 3. Results of ANOVA for effects of competition in the planting patch, orientation of patches, variation between microhabitats of origin, and variation among genotypes in vertical foraging traits of Ranunculus reptans.

\begin{tabular}{|c|c|c|c|c|c|}
\hline \multirow[b]{2}{*}{ Source of variation } & \multirow[b]{2}{*}{$\mathrm{df}$} & \multicolumn{2}{|c|}{$\begin{array}{l}\text { Vertical angle of first } \\
\text { internode }\end{array}$} & \multicolumn{2}{|c|}{ Stolon height } \\
\hline & & MS & $F$ & MS & $F$ \\
\hline Planting patch, $\mathrm{P}$ & 1 & 15437.61 & $30.00 * * *$ & 24544.85 & $32.85 * * *$ \\
\hline Orientation of patches, $\mathrm{O}$ & 1 & 270.67 & 0.73 & 1930.46 & 2.71 \\
\hline $\mathrm{P} \times \mathrm{O}$ & 1 & 64.25 & 0.18 & 7.01 & 0.02 \\
\hline Microhabitat of origin, M & 1 & 339.48 & 0.42 & 32.77 & 0.04 \\
\hline Genotype $(M), G(M)$ & 28 & 799.84 & $2.07 *$ & 745.24 & $1.62 \dagger$ \\
\hline $\mathrm{M} \times \mathrm{P}$ & 1 & 2637.64 & $5.13^{*}$ & 688.88 & 0.92 \\
\hline$G(M) \times P$ & 25 & 514.63 & 1.33 & 747.11 & $1.62 \dagger$ \\
\hline $\mathrm{M} \times \mathrm{O}$ & 1 & 4.25 & 0.01 & 13.57 & 0.02 \\
\hline $\mathrm{G}(\mathrm{M}) \times \mathrm{O}$ & 24 & 372.00 & 0.96 & 712.59 & $1.55 \dagger$ \\
\hline $\mathrm{M} \times \mathrm{P} \times \mathrm{O}$ & 1 & 3017.06 & $8.41^{*}$ & 2949.67 & $9.52 * *$ \\
\hline $\mathrm{G}(\mathrm{M}) \times \mathrm{P} \times \mathrm{O}$ & 13 & 358.80 & 0.93 & 309.80 & 0.68 \\
\hline Error & 46 & 386.16 & & 458.84 & \\
\hline
\end{tabular}

Notes: Experimental plants represented 30 genotypes sampled from microhabitats of two types. Plasticity in foraging responses is indicated by significant planting patch effects. Genetic variation in plasticity is indicated by significant planting patch $\times$ microhabitat of origin and planting patch $\times$ genotype interactions. The planting patch $\times$ microhabitat of origin interaction indicates differentiation between genotypes sampled from microhabitats of two types.

$\dagger P<0.1$; * $P<0.05$; ** $P<0.01$; *** $P<0.001$. 


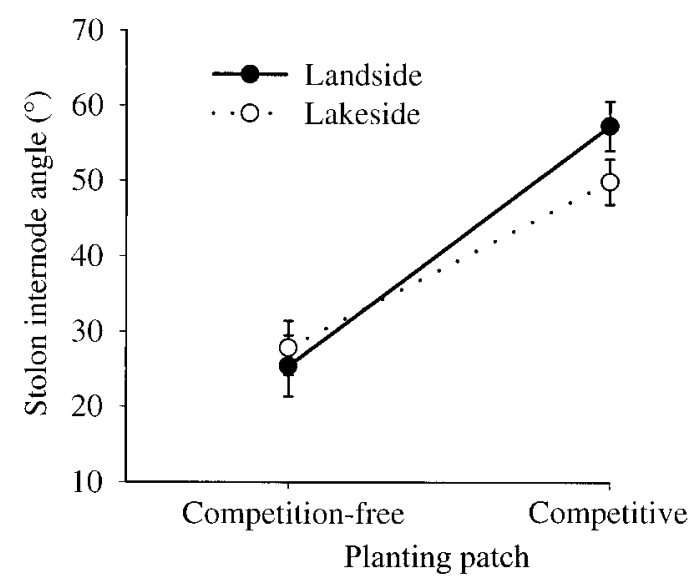

FIG. 2. The effect of competition in the planting patch on a vertical foraging trait of Ranunculus reptans, the vertical angle of the first stolon internode (Fig. 1). Experimental plants represented 30 genotypes sampled from competitive heterogeneous landside microhabitats (solid circles and solid lines) or from competition-free homogeneous lakeside microhabitats (open circles and dotted lines). As hypothesized, genotypes from the landside microhabitats were significantly more plastic (Table 3). Data are means \pm 1 SE.

facing trays: $97.9 \pm 2.1 \mathrm{~mm}$, Table 5). Genotypes originating from the landside microhabitat type were significantly more plastic (166\%) in specific internode length than genotypes from the lakeside microhabitat type (Fig. 3, microhabitat $\times$ planting patch interaction in Table 5). This indicates genetic differentiation in horizontal foraging respones between the two microhabitat types.
TABLE 4. Results of ANOVA for effects of initial length of the longest leaf, competition in planting patch, orientation of patches on and variation between microhabitats of origin, and variation among genotypes in length of the longest leaf in the experiment with Ranunculus reptans.

\begin{tabular}{lrrl}
\hline \hline \multicolumn{1}{c}{ Source of variation } & df & \multicolumn{1}{c}{ MS } & $F$ \\
\hline Initial leaf length & 1 & 520.01 & $6.49^{*}$ \\
Planting patch, P & 1 & 431.60 & $4.98^{*}$ \\
Orientation of patches, O & 1 & 376.59 & $5.38^{*}$ \\
P $\times$ O & 1 & 14.86 & 0.19 \\
Microhabitat of origin, M & 1 & 62.07 & 0.23 \\
Genotype(M), G(M) & 28 & 265.02 & $3.31^{* * *}$ \\
M $\times$ P & 1 & 32.37 & 0.37 \\
G(M) $\times$ P & 27 & 86.70 & 1.08 \\
$\times$ O & 1 & 41.15 & 0.59 \\
G(M) $\times$ O & 27 & 69.94 & 0.87 \\
M $\times$ P $\times$ O & 1 & 3.24 & 0.04 \\
G(M) $\times$ P $\times$ O & 25 & 78.48 & 0.98 \\
Error & 107 & 80.13 & \\
\hline
\end{tabular}

Notes: Experimental plants represented 30 genotypes sampled from two microhabitat types. Plasticity in foraging responses is indicated by significant planting patch effects. Genetic variation in plasticity is indicated by significant planting patch $\times$ microhabitat of origin and planting patch $\times$ genotype interactions. The planting patch $\times$ microhabitat of origin interaction indicates differentiation between genotypes sampled from microhabitats of two types.

$* P<0.05$; *** $P<0.001$.

\section{Benefits of plastic foraging responses}

The effect of plasticity (regression coefficient $\beta$ in Eq. 1) in the vertical angle of the first internode on the fitness measures number of rosettes and of flowers was significantly positive (Fig. 4; Table 6). Plasticity in stolon height had a significantly positive effect on the number of rooted rosettes (Table 6). Plasticity in spe-

TABLE 5. Results of ANOVA for the effects of competition in planting patch, orientation of patches on and variation between microhabitats of origin, and variation among genotypes for the combined length of the first four internodes and the specific length of the first four internodes in the experiment with Ranunculus reptans.

\begin{tabular}{|c|c|c|c|c|c|}
\hline \multirow[b]{2}{*}{ Source of variation } & \multirow[b]{2}{*}{ df } & \multicolumn{2}{|c|}{$\begin{array}{l}\text { Combined length of first } \\
\text { four internodes }\end{array}$} & \multicolumn{2}{|c|}{$\begin{array}{l}\log (\text { specific length of first } \\
\text { four internodes })\end{array}$} \\
\hline & & MS & $F$ & MS & $F$ \\
\hline Planting patch, $\mathrm{P}$ & 1 & 2844.75 & $9.50 * *$ & 0.19700 & $15.62 * * *$ \\
\hline Orientation of patches, $\mathrm{O}$ & 1 & 3533.14 & $7.21 *$ & 0.00531 & 0.73 \\
\hline $\mathrm{P} \times \mathrm{O}$ & 1 & 248.15 & 0.74 & 0.00288 & 0.44 \\
\hline Microhabitat, M & 1 & 72.73 & 0.12 & 0.00001 & 0.00 \\
\hline Genotype(M), G(M) & 28 & 582.09 & 1.38 & 0.02162 & 1.82 \\
\hline $\mathrm{M} \times \mathrm{P}$ & 1 & 36.63 & 0.12 & 0.05975 & $4.74 *$ \\
\hline $\mathrm{G}(\mathrm{M}) \times \mathrm{P}$ & 27 & 299.48 & 0.71 & 0.01261 & 1.06 \\
\hline $\mathrm{M} \times \mathrm{O}$ & 1 & 270.41 & 0.55 & 0.02541 & $3.51 \dagger$ \\
\hline $\mathrm{G}(\mathrm{M}) \times \mathrm{O}$ & 27 & 490.16 & 1.16 & 0.00725 & 0.61 \\
\hline $\mathrm{M} \times \mathrm{P} \times \mathrm{O}$ & 1 & 85.76 & 0.26 & 0.02716 & $4.18 \dagger$ \\
\hline $\mathrm{G}(\mathrm{M}) \times \mathrm{P} \times \mathrm{O}$ & 22 & 334.97 & 0.79 & 0.00651 & 0.55 \\
\hline Error & 76 & 421.40 & & 0.01189 & \\
\hline
\end{tabular}

Notes: The specific length of the first four internodes was log-transformed prior to analysis. Experimental plants represented 30 genotypes sampled from microhabitats of two types. Plasticity in foraging responses is indicated by significant planting patch effects. Genetic variation in plasticity is indicated by significant planting patch $\times$ microhabitat of origin and planting patch $\times$ genotype interactions. The planting patch $\times$ microhabitat of origin interaction indicates differentiation between genotypes sampled from microhabitats of two types.

$\dagger P<0.1 ; * P<0.05$; ** $P<0.01$; *** $P<0.001$. 


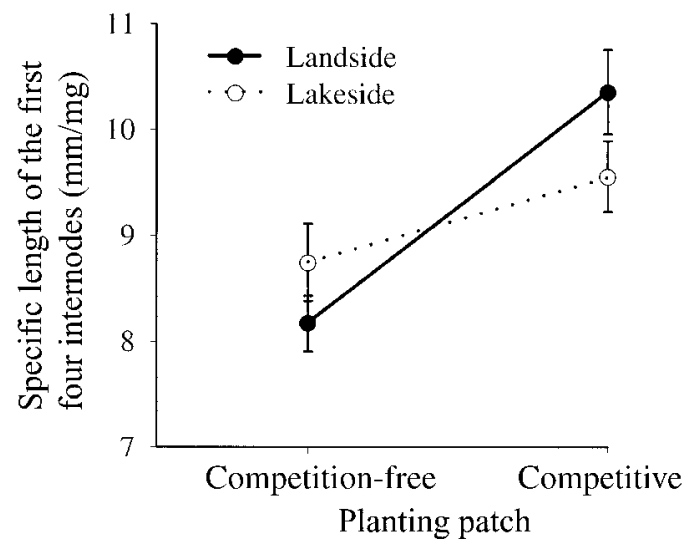

FIG. 3. The effect of competition in the planting patch on a horizontal foraging trait of Ranunculus reptans, the specific length of the first four internodes. Experimental plants represented 30 genotypes sampled from the landside microhabitat (solid circles and solid lines) or from the lakeside microhabitat (open circles and dotted lines). As hypothesized, genotypes from the landside microhabitat type were significantly more plastic (Table 5 ). Error bars indicate $\pm 1 \mathrm{SE}$.

cific internode length had a significantly positive effect on the number of rosettes and flowers (Table 6). These results indicate benefits of plasticity in both vertical and horizontal foraging traits. Plasticity in leaf and internode length, however, had negative effects on the number of flowers (Table 6) but not on other fitness measures (Table 6). These negative effects were significant when we used two-tailed tests (both $P<0.05$ ), and may suggest costs of plasticity in these traits.

\section{Discussion}

We first compare the plastic foraging responses found in Ranunculus reptans with the few other studies on plastic foraging responses to competition in clonal plants. We then discuss genetic variation and fitness consequences of these responses and draw conclusions on adaptation.

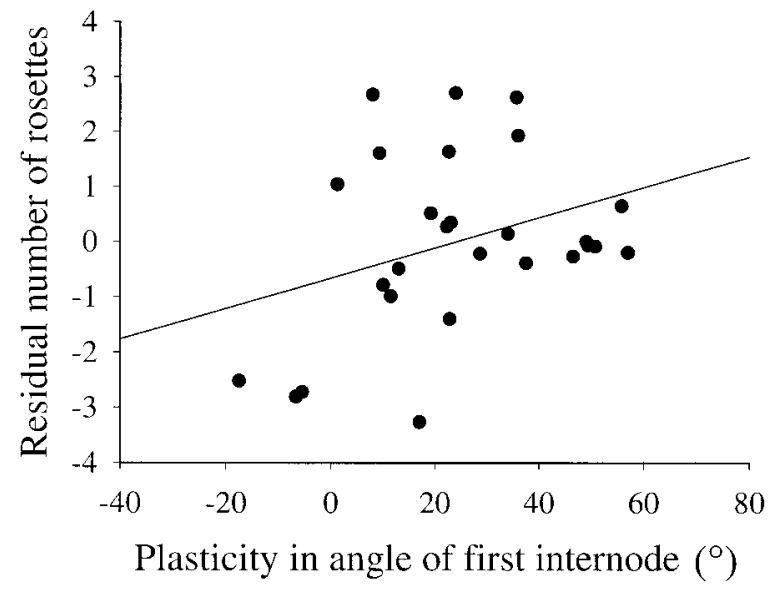

FIG. 4. Illustration of the significantly positive regression coefficient ( $\beta=0.363$, see Eq. 1 ; Table 6 ) of plasticity in the vertical angle of the first internode in response to competition in the planting patch on the number of rosettes of Ranunculus reptans. The residual number of rosettes was obtained from the regression of the number of rosettes averaged over both planting patches on the vertical angle of the first internode averaged over both planting patches. Experimental plants represented 30 genotypes.

\section{Plastic foraging responses}

Our results indicate that $R$. reptans may forage vertically for light and horizontally for competition-free patches (Table 1). Plants planted into the competitive patches produced longer stolon internodes and branched less frequently than plants planted into the competition-free patches. Moreover, plants of $R$. reptans planted into the competitive patches produced longer leaves and their stolons grew higher than the ones of plants planted into the competition-free patches. These results are in line with plastic foraging responses to competition reported for three other stoloniferous plants. In Glechoma hederacea, stolons and petioles were significantly longer when they were grown in competition with the grass Lolium perenne than when

TABLE 6. Tests for fitness benefits of plasticity in vertical and horizontal foraging traits.

\begin{tabular}{|c|c|c|c|c|}
\hline Trait & Biomass & $\begin{array}{c}\text { No. } \\
\text { rosettes }\end{array}$ & $\begin{array}{c}\text { No. } \\
\text { rooted } \\
\text { rosettes }\end{array}$ & $\begin{array}{l}\text { No. } \\
\text { flowers }\end{array}$ \\
\hline \multicolumn{5}{|l|}{ Vertical foraging } \\
\hline Vertical angle of first internode & 0.101 & $0.363 *$ & 0.109 & $0.401 *$ \\
\hline Stolon height & -0.008 & 0.223 & $0.345^{*}$ & 0.248 \\
\hline Length of longest leaf & -0.028 & -0.066 & 0.114 & -0.414 \\
\hline \multicolumn{5}{|l|}{ Horizontal foraging } \\
\hline Proportion of stolons initiated into & & 0020 & 0.01 & -0100 \\
\hline Combined length of first four internodes & 0.140 & $\begin{array}{r}0.039 \\
-0.092\end{array}$ & $\begin{array}{l}-0.101 \\
-0.056\end{array}$ & $\begin{array}{l}-0.100 \\
-0.414\end{array}$ \\
\hline Specific length of first four internodes & -0.023 & $0.351 *$ & 0.039 & $0.316^{*}$ \\
\hline
\end{tabular}

Notes: The table lists standardized regression coefficients of fitness measures on plasticity in foraging traits ( $\beta$ in Eq. 1). All values are based on genotypic means. Fitness was measured as biomass and the numbers of rosettes, rooted rosettes, and flowers. Benefits of plasticity in foraging traits are indicated by positive regression coefficients.

$* P<0.05$. 
grown without competition (Price and Hutchings 1996). In the stoloniferous Prunella vulgaris, the distance between ramets was larger when plants were grown in competition with $L$. perenne than without competition (Schmid 1986). In a field study, internodes of Ranunculus repens (not to be confused with $R$. reptans) were found to be significantly shorter on mole hills than in the surrounding vegetation (Waite 1994).

Rhizomatous plants, on the other hand, seem to respond differently to competition than stoloniferous ones. The rhizomatous grass Amphibromus scabrivalvis grew more compact in competition with $L$. perenne than without competition (Cheplick 1997, Cheplick and Gutierrez 2000), and in the rhizomatous pseudo-annual Glaux maritima the length of internodes decreased with increasing competition (L. Jerling, unpublished data, as cited in Sutherland and Stillman [1988]). This may reflect the fact that rhizomes grow belowground. While rhizomes cannot directly detect shading by competitors, which would be necessary for internode elongation responses (i.e., active plasticity), internode lengths in rhizomatous plants may be reduced under competition because of resource limitation (i.e., passive plasticity).

Genetic variation in foraging responses and genetic differentiation between microhabitats of origin

For the vertical angle of the first stolon internode, stolon height, and specific internode length, we found significant, marginally significant, and significant variation, respectively, among genotypes in their plastic response to competition (Tables 3 and 5). As far as this variation reflects additive genetic variation, it suggests that both vertical and horizontal foraging responses are heritable, which is one prerequisite for foraging to be in the process of adaptation.

Studies on genetic variation in plastic foraging responses of clonal plants are scarce. In Festuca rubra, significant variation in plasticity in the architecture of rhizomes (i.e., in horizontal foraging) has been found among 12 genotypes in response to the red-to-far-red ratio of light, but not in shoot length (i.e., not in vertical foraging, Skálová et al. 1997). In one study with 12 and another study with 14 genotypes of Amphibromus scabrivalvis, there was no significant variation among the genotypes in plasticity in interramet distances (i.e., horizontal foraging) in response to competition (Cheplick 1997, Cheplick and Gutierrez 2000). Variation among 14 genotypes of Elymus lanceolatus in plasticity in ramet placement (i.e., horizontal foraging) in response to nutrient availability was also not significant (Humphrey and Pyke 1997). In these studies, genetic variation in foraging responses was not studied with material from different microhabitat types.

We found significant differentiation between genotypes from the different microhabitat types in the vertical angle of the first internode and in specific internode length (Tables 3 and 5). As hypothesized, geno- types from the heterogeneous competitive landside were more plastic than genotypes from the homogeneous competition-free lakeside for both traits (Figs. 3 and 4). In a previous study on clonal integration in $R$. reptans, we found a similar result. Leaf and internodeelongation responses of shaded ramets were more strongly stimulated by clonal integration in genotypes from the landside microhabitat than in genotypes from the lakeside microhabitat (van Kleunen et al. 2000a). Genetic differentiation within plant populations has been frequently reported, and can often be attributed to different intensities of selection pressures in different microhabitats, even over short distances (Linhart and Grant 1996). Because foraging responses of $R$. reptans are likely to be more beneficial in the competitive heterogeneous landside than in the competition-free homogeneous lakeside, the observed genetic differentiation in foraging responses seems to be adaptive. However, to further support this hypothesis, we tested whether plastic foraging increased plant fitness.

\section{Fitness consequences of plastic-foraging responses}

To our knowledge, this is the second empirical study testing for benefits of plastic-foraging responses in a clonal plant and the first one to find such benefits. Humphrey and Pyke (1997) did not find a benefit of plasticity in ramet placement in terms of biomass production of 14 genotypes of Elymus lanceolatus growing in a patchy-nutrient environment. Modeling studies suggest that the magnitude of empirically found foraging responses are often too small to result in effective ramet placement (i.e., aggregation of ramets in benign patches; Cain 1994, Oborny 1994, Cain et al. 1996). In these models, however, the null model, corresponding to a lack of foraging, is that growth form is identical in benign and unfavorable patches. In unfavorable patches, however, resource limitation may result in shorter internodes (passive plasticity). Therefore a more appropriate null model for active plasticity in internode length would be shorter internodes under unfavorable condititions than under benign conditions. This would imply that foraging responses observed in empirical studies may be more effective than expected from these modeling studies.

We studied fitness consequences of plastic foraging responses of $R$. reptans with selection-gradient analysis. For plasticity in the vertical angle of the first internode, in stolon height, and in specific internode length, we detected benefits in terms of several fitness measures. For leaf and internode length, we detected negative effects of plasticity on flower production. This may suggest that there were costs of plasticity for these traits (van Kleunen et al. 2000b). The other fitness measures, however, were not negatively affected by plasticity in leaf and internode length. Overall, our results indicate that there are fitness benefits of both vertical and horizontal foraging responses in $R$. reptans.

Compared with the natural situation, fitness benefits 
of plastic height growth of stolons may have been underestimated in our experiment. Height growth of stolons not only exposes more photosynthetic tissue in the higher strata of the vegetation, but also exposes flowers. In the natural habitat this may attract more pollinators, and as a consequence increase seed set (Donnelly et al. 1998).

\section{Conclusion}

So far, plastic foraging responses in clonal plants have often implicitly been assumed to constitute an adaptation, although empirical evidence was lacking. We found significant genetic variation in and fitness benefits of both vertical and horizontal foraging responses. These are the two prerequisites before plastic foraging responses can be considered to be in the process of adaptation. Moreover, the genetic variation in plasticity of both horizontal and vertical foraging traits could in part be attributed to the different microhabitat types from which the genotypes originated. In line with the hypothesis of adaptive plasticity, plastic foraging responses were larger in genotypes from the competitive, heterogeneous microhabitats than in genotypes from the competition-free, homogeneous ones. Based on these findings, we conclude that plastic foraging constitutes an adaptation, at least in the stoloniferous $R$. reptans.

\section{ACKNOWLEDGMENTS}

We thank Adelaide Stoppiello and Gillian Rutherford for practical assistance, and Gregory Cheplick, Marc Kéry, Josh Van Buskirk, and an anonymous referee for helpful comments on earlier drafts of this manuscript. We acknowledge financial support by the Swiss National Science Foundation (Grant 3149728.96).

\section{Literature Cited}

Bazzaz, F. A. 1991. Habitat selection in plants. American Naturalist 137:S116-S130.

Bell, A. D. 1984. Dynamic morphology: a contribution to plant population ecology. Pages 48-65 in R. Dirzo and J. Sarukhan, editors. Perspectives on plant population ecology. Sinauer, Sunderland, Massachusetts, USA.

Birch, C. P. D., and M. J. Hutchings. 1992. Stolon growth and branching in Glechoma hederacea L.: an application of a plastochron index. New Phytologist 122:545-551.

Bradshaw, A. D. 1965. Evolutionary significance of phenotypic plasticity in plants. Advanced Genetics 13:115155.

Cain, M. L. 1994. Consequences of foraging in clonal plant species. Ecology 75:933-944.

Cain, M. L., D. A. Dudle, and J. P. Evans. 1996. Spatial models of foraging in clonal plant species. American Journal of Botany 83:76-85.

Cheplick, G. P. 1997. Responses to severe competitive stress in a clonal plant: differences between genotypes. Oikos 79: 581-591.

Cheplick, G. P., and C. M. Gutierrez. 2000. Clonal growth and storage in relation to competition in genets of the rhizomatous perennial Amphibromus scabrivalvis. Canadian Journal of Botany 78:537-546.

de Kroon, H., and J. Knops. 1990. Habitat exploration through morphological plasticity in two chalk grassland perennials. Oikos 59:39-49.

de Kroon, H., J. F. Stuefer, M. Dong, and H. J. During. 1994.
On plastic and non-plastic variation in clonal plant morphology and its ecological significance. Folia Geobotanica and Phytotaxonomy 29:123-138.

Dong, M., and M. G. Pierdominici. 1995. Morphology and growth of stolons and rhizomes in three clonal grasses, as affected by different light supply. Vegetatio 116:25-32.

Donnelly, S. E., C. J. Lortie, and L. W. Aarssen. 1998. Pollination in Verbascum thapsus (Scrophulariaceae): the advantage of being tall. American Journal of Botany 85:16181625.

Fischer, M., R. Husi, D. Prati, M. Peintinger, M. van Kleunen, and B. Schmid. 2000. RAPD variation among and within small and large populations of the rare clonal plant $R a$ nunculus reptans (Ranunculaceae). American Journal of Botany 87:1128-1137.

Gould, S. J., and R. C. Lewontin. 1978. The spandrels of San Marco and the Panglossian paradigm: a critique of the adaptationist programme. Proceedings of the Royal Society of London 205:581-598.

Harper, J. L. 1981. The concept of populations in modular organisms. Pages 53-77 in R. M. May, editor. Theoretical ecology: principles and applications. Blackwell Scientific, Oxford, UK.

Hess, H. E., E. Landolt, and R. Hirzel. 1980. Flora der Schweiz. Volume 2. Birkhäuser, Basel, Switzerland.

Huber, H. 1996. Plasticity of internodes and petioles in prostrate and erect Potentilla species. Functional Ecology 10: 401-409.

Huber, H., A. Fijan, and H. J. During. 1998. A comparative study of spacer plasticity in erect and stoloniferous herbs. Oikos 81:576-586.

Huber, H., and J. F. Stuefer. 1997. Shade-induced changes in the branching pattern of a stoloniferous herb: functional response or allometric effect? Oecologia 110:478-486.

Humphrey, L. D., and D. A. Pyke. 1997. Clonal foraging in perennial wheatgrasses: a strategy for exploiting patchy soil nutrients. Journal of Ecology 85:601-610.

Hutchings, M. J., and H. de Kroon. 1994. Foraging in plants: the role of morphological plasticity in resource acquisition. Advances in Ecological Research 25:159-238.

Hutchings, M. J., and A. J. Slade. 1988. Morphological plasticity, foraging and integration in clonal perennial herbs. Pages 83-109 in A. J. Davy, M. J. Hutchings, and A. R. Watkinson, editors. Plant population ecology. Blackwell Scientific, Oxford, UK.

Lande, R., and S. J. Arnold. 1983. The measurement of selection on correlated characters. Evolution 37:1210-1226.

Lewontin, R. C. 1984. Adaptation. Pages 235-251 in E. Sober, editor. Conceptual issues in evolutionary biology. An anthology. Bradford Books, Cambridge, UK.

Linhart, Y. B., and M. C. Grant. 1996. Evolutionary significance of local genetic differentiation in plants. Annual Review in Ecology and Systematics 27:237-277.

Norusis, M. J. 1999. SPSS for Windows. Release 10.0.5. SPSS, Chicago, Illinois, USA.

Novoplansky, A., D. Cohen, and T. Sachs. 1990. How portulaca seedlings avoid their neighbours. Oecologia 82:490493.

Oborny, B. 1994. Spacer length in clonal plants and the efficiency of resource capture in heterogeneous environments: a Monte Carlo simulation. Folia Geobotanica and Phytotaxonomy 29:139-158.

Payne, R. W., P. W. Lane, P. G. N. Digby, S. A. Harding, P. K. Leech, G. W. Morgan, A. D. Todd, R. Thompson, G. Tunicliffe Wilson, S. J. Welham, and R. P. White. 1993. Genstat 5 reference manual. Clarendon Press, Oxford, UK.

Pitelka, L. F., and J. W. Ashmun. 1985. Physiology and integration of ramets in clonal plants. Pages 399-435 in J. B. C. Jackson, L. W. Buss, and R. E. Cook, editors. Pop- 
ulation biology and evolution of clonal organisms. Yale University Press, New Haven, Connecticut, USA.

Prati, D. 1998. The genetics and life-history evolution of the clonal plant Ranunculus reptans. Dissertation. University of Zürich, Zürich, Switzerland.

Prati, D., and M. Peintinger. 2000. Biological flora of Central Europe: Ranunculus reptans L. Flora 195:135-145.

Price, E. A. C., and M. J. Hutchings. 1996. The effect of competition on growth and form in Glechoma hederacea. Oikos 75:279-290.

Schmid, B. 1986. Spatial dynamics and integration within clones of grassland perennials with different growth form. Proceedings of the Royal Society of London 228:173-186.

Schmid, B. 1990. Some ecological and evolutionary consequences of modular organization and clonal growth in plants. Evolutionary Trends in Plants 4:25-34.

Schmitt, J., S. A. Dudley, and M. Pigliucci. 1999. Manipulative approaches to testing adaptive plasticity: phytochrome-mediated shade-avoidance responses in plants. American Naturalist 154:S43-S54.

Skálová, H., S. Pechácková, J. Suzuki, T. Herben, T. Hara, V. Hadincová, and F. Krahulec. 1997. Within population genetic differentiation in traits affecting clonal growth: Festuca rubra in a mountain grassland. Journal of Evolutionary Biology 10:383-406.

Slade, A. J., and M. J. Hutchings. 1987a. Clonal integration and plasticity in foraging behaviour in Glechoma hederacea. Journal of Ecology 75:1023-1036.
Slade, A. J., and M. J. Hutchings. 1987b. The effects of light intensity on foraging in the clonal herb Glechoma hederacea. Journal of Ecology 75:639-650.

Solangaarachchi, S. M., and J. L. Harper. 1987. The effect of canopy filtered light on the growth of white clover Trifolium repens. Oecologia 72:372-376.

Stuefer, J. F. 1996. Potential and limitations of current concepts regarding the response of clonal plants to environmental heterogeneity. Vegetatio 127:55-70.

Sutherland, W. J., and R. A. Stillman. 1988. The foraging tactics of plants. Oikos 52:239-244.

van Kleunen, M., M. Fischer, and B. Schmid. 2000a. Clonal integration in Ranunculus reptans: by-product or adaptation? Journal of Evolutionary Biology 13:237-248.

van Kleunen, M., M. Fischer, and B. Schmid. 2000b. Costs of plasticity in foraging characteristics of the clonal plant Ranunculus reptans. Evolution 54:1947-1955.

Via, S. 1987. Genetic constraints on the evolution of phenotypic plasticity. Pages 47-70 in V. Loeschke, editor. Genetic constraints on the evolution of phenotypic plasticity. Springer-Verlag, Berlin, Germany.

Waite, S. 1994. Field evidence of plastic growth responses to habitat heterogeneity in the clonal herb Ranunculus repens. Ecological Research 9:311-316.

Weis, A. E., and W. L. Gorman. 1990. Measuring selection on reaction norms: an exploration of the Eurosta-Solidago system. Evolution 44:820-831. 